\title{
Historia, ficción y evidencialidad en la épica colonial*
}

\author{
History, Fiction and Evidentiality \\ at Colonial Epic
}

\section{EugEnia OrTiz GambetTA}

Instituto de Investigaciones en Humanidades y Ciencias Sociales

Universidad Nacional de La Plata

La Plata, Prov. de Buenos Aires. Argentina

Facultad de Filosofía y Letras

Universidad Católica Argentina

Ciudad Autónoma de Buenos Aires. Argentina

eortiz@fahce.unlp.edu.ar

Orcid ID 0000-0001-5316-1615
Resumen: En la épica colonial, como en otros textos de la conquista europea en América, el relato histórico y el relato maravilloso conviven con el trasfondo de la revolución epistemológica, así como con la nueva recepción de la preceptiva aristotélica en la Italia y la España del Renacimiento. Este trabajo muestra cómo, en el poema épico Argentina y conquista del Río de la Plata (1602) de Martín del Barco Centenera, la voz épica se codifica mediante rasgos de evidencialidad y ciertos recursos retóricos que construyen el punto de vista moralizante del testimonio.

Palabras clave: Épica americana. Evidencialidad. Historia. Barco Centenera. Río de la Plata.

\begin{abstract}
This paper aims to consider Martin del Barco Centenera's Argentina y conquista del Río de la Plata (1602) as a blending of history and fiction, in the context of an epistemic revolution that took place during the European Renaissance Era and the preceptive reading of Aristotle's Poetics in Italy and Spain. This paper exposes how this epic poem was elaborated with evidentially modalizations and other rhetoric resources to provide a credible testimony and its moralizating point of view.
\end{abstract}

Keywords: Latinamerican Epic. Evidentiality. History. Barco Centenera. River Plate.

\footnotetext{
* Agradezco a José Aragüés Aldaz que me facilitase su estudio sobre la retórica del exemplum, del que tomo la formulación del binomio res certa/res ficta (39-42) y las implicaciones retóricas y morales del exemplum, tan adecuado para este trabajo. También agradezco a mi amigo y colega Álvaro Caso Bello que tuvo la amabilidad de facilitarme bibliografía para esta investigación. Por último, el enfoque del estudio de la evidencialidad en el poema de Barco Centenera es uno de los resultados de mi estancia de investigación en la Universität Heidelberg (Alemania) bajo la ayuda de un estipendio del IAZ (Iberoamerica-Zentrum).
} 


\section{INTRODUCCIÓN}

a épica forma parte del discurso colonial de América Latina, aunque aún no ha recibido suficiente atención como fenómeno ni como corpus. ${ }^{1} \mathrm{Si}$ el discurso colonial latinoamericano es un entramado que emerge de la consideración de un archivo conformado por material de todo tipo, y si los estudios literarios amplían la consideración del discurso colonial a partir de la indagación de ese archivo, es indispensable que también se reconsideren no solo las crónicas mestizas, por ejemplo (cuya propuesta suele ser menos previsible y más innovadora), sino también aquellos textos imperiales, es decir, aquellos engarzados sin ambages en las tradiciones culturales europeas. De una y otra manera, estos textos elaborados en el fragor de la empresa de conquista presentan una fidelidad dudosa con sus modelos y una continuidad con deslindes más o menos explícitos. ${ }^{2}$

Dentro de los textos más innovadores se incluye una serie de testimonios escriturarios divergentes, algunos pertenecientes a analfabetos o semi-analfabetos que, empujados por la experiencia de las empresas y la necesidad de hacer relación de méritos, accedían al mundo de la escritura (Oesterricher 13). Por otro lado, también decidían escribir sus propias obras individuos que, aunque alfabetizados y cultos, no lo hubieran hecho de haberse encontrarse en otra situación. Todos los documentos, desde los más básicos a los más elaborados, respondían a un horizonte de expectativas, a modelos retóricos y preceptivos más o menos estables, mientras crecía la demanda de historias sobre América en la Europa del siglo XVI. Dentro de estos productos escriturarios, el género épico fue uno de los cultivados con más entusiasmo ya que respondía a los anhelos de alta literatura y a la creciente influencia del humanismo italiano.

La épica hispánica de la conquista no ha tenido, hasta los trabajos de Firbas, Vega y Vilà y Marrero-Fente, una consideración específica y distintiva dentro del sistema literario colonial, seguramente por las implicancias im-

1. Ver el trabajo dirigido por Paul Firbas, por mencionar una recopilación realizada hace más de diez años y que es pionera en el redescubrimiento del tema.

2. Es muy actual el debate sobre cuál es la mirada que merecen estos textos, cuáles son los límites del sistema, qué diferencias hay entre archivo y corpus. Para Valeria Añón, después de haber planteado "nuevas perspectivas" (Adorno) y haber ampliado la mirada del problema con el concepto de "semiosis cultural colonial" (Mignolo) la pregunta es qué texto debe ser considerado propio del sistema literario colonial latinoamericano y porqué, pero también, dónde queda la cuestión de la literaturidad en estas consideraciones (Añón 252). 
perialistas del género, a contramano de las tendientes lecturas criollistas y poscoloniales. ${ }^{3}$ Sin embargo, es interesante volver a considerar estos poemas por las proyecciones políticas y colectivas que tuvieron unos y pretendieron otros, y por la centralidad del género dentro del mundo hispánico durante los siglos XVI y XVII. Entre las modalidades textuales producidas durante el despliegue de las empresas imperiales, la poesía épica tuvo un gran impacto: por un lado, transmitía datos referenciales y experiencias en primera persona; por el otro lado, acompañaba el discurso glorioso de la Corona mediante un modo acorde que, sobre todo, tenía una alta consideración en la cultura letrada europea gracias al desembarco de la épica renacentista italiana en España durante el siglo XVI y el auge de la preceptiva de la mano de las traducciones de la Poética de Aristóteles (Montaner 19). Estos dos factores, sumados a la preeminencia de la historia en la teoría poética peninsular, son claves para recontextualizar la épica colonial y en especial, algunas obras en las que resulta más urgente dar cuenta de ciertos rasgos de enunciación y factura.

Las crónicas en general y la épica americana en particular, así, deben ser comprendidas en el contexto del furor por la epopeya moderna en Europa, pero también en su relación con las preceptivas renacentistas y la emergencia de un cambio epistemológico, tal como sostiene Montaner:

Resulta revelador el cambio de jerarquía epistemológica de las disciplinas que se efectúa a lo largo del siglo XVI, pues el criterio deja de ser el filosófico de la universalidad para comenzar a serlo el científico de la veracidad (aunque previamente, en la línea muy humanista, había sido el ético de la ejemplaridad y capacidad persuasiva en lo moral). En consecuencia, la épica pasará de considerarse la reina de las manifestaciones literarias [...] a serlo como una forma primitiva y poco rigurosa del discurso histórico, una suerte de prisca bistoria o protohistoriografía. (20)

3. La épica americana conforma un lote desprestigiado de epopeyas, con excepción de la eminente Araucana, obra de éxito absoluto en su época, estudiada largamente como fenómeno casi aislado. Marrero-Fente da cuenta en su estudio de los trabajos sobre el área que desde el libro de Frank Pierce (1968) han apuntado a revindicar un género muy desprestigiado y poco atendido en general: los casos son tan contados que la enumeración es muy completa (Marrero-Fente 14). Marrero también hace alusión a que el pobre tratamiento de la épica americana en los estudios literarios es muy similar a lo que sucede, en general, con la épica peninsular del quinientos. 
El tránsito de pasar de ser excelsa poesía a forma menor de la historia aparece en los debates de los teóricos neoaristotélicos para quienes la historia era un género literario. Es decir, para estos, la verosimilitud no había que considerarla en el contexto de la deixis, en lo intraliterario, sino en lo extraliterario. Así, el discurso histórico

solo se diferencia de los demás por su particular aptum retórico y por una cierta restricción de la inventiva del autor, quien únicamente podía apartarse de la verdad (es decir, de la relación del registro factual) en elementos digresivos, como descripciones o discursos, pero siempre dentro del posibilismo, es decir, de lo uerisimile, habida cuenta que [...] la mayor parte de estos autores renacentistas conciben este en términos extraliterarios. (Montaner 20)

Por su parte, María José Vega señala que en los prólogos de los poemas épicos hispánicos del Quinientos no hay influencia de las teorías neoaristotélicas y hay otra consideración de la épica como género histórico (108). En primer lugar, en esos prólogos se abogaba por "la superioridad moral y ontológica de lo verdadero sobre lo fingido" (109) y se definía la épica como género histórico, y "como fuente de experiencia y moralidad, como compendio de sabiduría política, como suma de exempla, consilia y sententiae" (Vega 109). El poema heroico era para ellos, una obra verdadera, una forma de historia de lo más ejemplar (109). La fábula o invención en este esquema era una concesión que debía ir con el tipo de imitatio, algo que se engarzaba en la historia: se consideraba apropiado el uso de la fábula en las partes "accesorias del texto (descripciones, digresiones, ejemplos, discursos, arengas)” (114). En suma, los preceptistas renacentistas neo-aristotélicos, pero también los prólogos del 1500, consideraban que el discurso histórico y el poético podían tener los mismos referentes (lo evenemencial) aunque cada uno los tratase de manera diferente. Así, la verdad histórica era un concepto más complejo que la narración de lo factual y, en el testimonio, podía incluir un recurso retórico o una construcción de una forma imaginativa pensados para complacer el horizonte de expectativa del lector de esos textos.

De esta manera, para considerar la historia en la épica americana (los datos referenciales presentes en la forma poética), hay que tener en cuenta esta cuestión epistemológica y los condicionamientos materiales y conceptuales del entorno donde se produjo y se publicó la obra, incluido, desde luego, su 
horizonte ideológico. ${ }^{4}$ En el caso de la épica hispánica del XVI, se deberá considerar el entramado de prácticas de representación vinculadas a dos aspectos: en primer lugar, la épica como discurso del imperio español (cuyo modelo era, por entonces, Virgilio), su necesidad política y colectiva; en segundo lugar, la épica como narración de hechos muy recientes que todavía estaban en la memoria del pueblo (cuyo modelo era Lucano) y que abordaba una materia en sí misma poetizable -la conquista del Nuevo Mundo- que para muchos fue "heroica antes de ser contada" (Vega 107-08).

Tomando en cuenta estas preceptivas y la presión del cambio epistemológico analizaré cómo se imbrican el discurso histórico y el ficcional en el único poema épico rioplatense del siglo XVII, Argentina y conquista del Río de la Plata (1602) del arcediano Martín del Barco Centenera (Logrosán, España 1535-Lisboa, Portugal 1602) que es, a su vez, el primer testimonio en español sobre la llegada de los españoles a la región, ${ }^{5}$ poema en el que se encarna de diversas maneras la cuestión de la verdad histórica, la fantasía y la verosimilitud. Una posibilidad para abordar esta conjunción de aspectos es atender al lugar de enunciación del poema, punto de configuración de la subjetividad del testimonio y bisagra de los modos y recursos de representación. La voz épica, en este caso identificada con la de un participante de ciertos hechos relatados, desarrolla episodios percibidos por sus sentidos a veces y recogidos de terceras personas o tomados de diversas fuentes de información y referencias, otras tantas. ${ }^{6}$ En todos los casos, las experiencias y datos recogidos aparecen señalados lingüísticamente a lo largo del texto por medio de marcadores de evidencialidad, en especial, mediante verbos de percepción sensible pero también, a través de otros recursos como la elevación del sujeto y la inferencia. El des-

4. Hay que hacer, sin duda, el mismo ejercicio para entender la mirada crítica sobre estas obras por parte de los historiadores coloniales y criollos. En muchos de estos trabajos hay recurrentes alusiones al uso de poemas épicos como documentos contrastables con los hechos históricos. En diversas ocasiones, como en la lectura historicista del poema de Barco Centenera, al ser cuestionada la fidelidad de ciertos datos se menospreció la obra; por ejemplo, es el caso de Félix de Azara (40). Otro tanto sucedió con la épica hispánica del Quinientos en casi toda la historiografía decimonónica (Vega 108).

5. El primer testimonio de la conquista de la región fue la crónica de Ulrich Schmidl, Derrotero y viaje a España y las Indias, publicada por primera vez en alemán en Frankfurt en 1567 y recientemente reeditado por Loreley El Jaber en Argentina (2016).

6. Al decir de María José Vega, los archivos y documentos históricos eran centrales en la épica del 1500: "los autores épicos no solo se acogen al prestigio de la historia como arte mayor, sino también a sus protocolos de indagación y escritura, al modo de adquirir conocimientos y conferir testimonios, al uso de fuentes documentales y a la interrogación de testigos, al concepto, pues, de la verdad histórica como producto del método y de estudio" (111). 
glose de estos aspectos lingüísticos dará cuenta de los usos retóricos y la verosimilitud del testimonio.

\section{TESTIMONIO E HISTORIA: LA ENUNCIACIÓN DEL POEMA}

Argentina de Martín del Barco Centenera, además de ser casi el único testimonio editado de la expedición del Adelantado Juan Ortiz de Zárate, se conoce como un ejemplar de épica y como un hito dentro del sistema literario rioplatense. ${ }^{7}$ El documento es uno de los primeros que dan cuenta de la exploración y conquista de la región del Río de la Plata durante el siglo XVI, el territorio que Barco Centenera denomina en su obra "Argentina" y que incluye los actuales estados de Paraguay, Argentina, Uruguay y parte de Brasil. El poema es un relato de las dos primeras expediciones a la región (la de Juan Díaz de Solís entre 1515 y 1516, y la de Pedro de Mendoza en 1536), pero, además, en él el autor describe la expedición de Ortiz de Zárate, iniciada en 1572, desde su punto de vista como capellán de la empresa.

En cuanto a su aspecto formal, el texto copia el estilo y el metro de $L a$ Araucana (1569-1589) de Alonso de Ercilla. Barco Centenera también tuvo en cuenta la épica renacentista italiana al componer su poema, especialmente a Matteo Boiardo que, como en Ercilla, marcó el rumbo del entrecruce de los episodios reales y fantasiosos, el principio de enseñar deleitando, el uso de la octava real y la carencia de unidad narrativa. Argentina también se escribió teniendo presente El laberinto de Fortuna (1444) de Juan de Mena, al que cita en diversas ocasiones. Por otro lado, sin ser una parodia del género, el poema narra los acontecimientos de la conquista del Río de la Plata pero, en contraposición a la orientación natural del género, en vez de exaltar las hazañas del imperio, pone en tela de juicio la empresa y los jefes a quienes ridiculiza, en el estilo de la épica burlesca pero sin serlo en pleno sentido (Ortiz Gambetta 2016b, 74-79). ${ }^{8}$ A su vez, incluye anécdotas grotescas, resalta las figuras de algunos pobladores y narra las acciones de los piratas ingleses en el Océano $\mathrm{Pa}$ cífico como si fueran heroicas. Por su valor estético y sus imprecisiones histó-

7. Desde la edición de documentos realizada por Pedro de Ángelis en 1836, el texto fue considerado parte del sistema histórico y cultural del Río de la Plata, y desde la Historia de la literatura argentina de Ricardo Rojas hasta la Historia crítica... dirigida por Noé Jitrik forma parte del canon de la literatura colonial del país.

8. Es estimable la pregunta de la elección genérica o el molde épico en un poema con estas características, como sugiere Navascués (2016, 308-10). 
ricas, ha sido criticada duramente por los mismos que la rescataron (ver Rojas y Gutiérrez, por ejemplo) y a pesar de su pobre factura, la obra tuvo una estimable trascendencia como documento histórico en España y en el Río de la Plata, y como referente literario hasta hoy.

Poco se sabe del autor más allá de que fue capellán de la expedición de Ortiz de Zárate, que fue nombrado arcediano de la iglesia de Asunción, que estuvo en el primer concilio de Lima y que fue trasladado de jurisdicción eclesiástica por varias acusaciones y causas abiertas en su contra por conducta inmoral (Durán 359). También hay una conjetura sobre su presencia en la segunda fundación de Buenos Aires y su asistencia en una de las hambrunas que sufrió la ciudad, poco antes de regresar a Europa (Wright/Nekhom 69). Una vez en Lisboa, ciudad en la que se incorporó al servicio del marqués de Mora, virrey a finales del siglo XVI, publicó el poema Argentina y conquista del Río de la Plata, el mismo año de su muerte (Wright/Nekhom 59; Gandía 69).

El texto ofrece datos sobre las empresas militares, léxico e información etnográfica sobre los guaraníes y otros pueblos de la región, aspectos que llamaron la atención en su momento y que hasta generaron insumos para el imaginario de la región en los autores del romanticismo local. ${ }^{9}$ El relato de los hechos vividos por el arcediano y las empresas anteriores se inscribe en la estructura formal de la octava real. Así se reconstruyen los diversos episodios y descripciones de espacios, usos y costumbres de los indígenas, y los enfrentamientos bélicos contra ellos, los episodios de las incursiones piratas, la hambruna de Buenos Aires y la convocatoria y disputas internas del Concilio de Lima. Toda esta materia fáctica está presentada de manera combinada con anécdotas cercanas al discurso de lo maravilloso, en una llamativa composición en la que predominan las huellas lingüísticas del enunciador en relación con la veracidad de lo narrado.

\section{FUENTES DE INFORMACIÓN Y EVIDENCIALIDAD}

El punto de vista del poema de Barco Centenera presenta una codificación lingüística que se comprende mejor mediante el análisis de los rasgos de evidencialidad y las atribuciones de fuentes escritas y orales. Los elementos lingüís-

9. Autores como Magariños Cervantes, Juan M. Gutiérrez, Adolfo Berro, José Zorrilla de San Martín, entre otros, han aludido el texto como fuente de poemas y novelas. Ver Ortiz Gambetta (2016a). 
ticos evidenciales hacen referencia a las fuentes de información en las que se basa el texto, cuyos niveles de inferencialidad y experiencia están marcados semánticamente. Este abordaje analítico del testimonio permite corporizar la voz que construye el relato y considerar su particularidad a la luz de la tradición discursiva a la que pertenece. ${ }^{10}$

En definición de Wachtmeister Bermúdez, la evidencialidad es el "dominio semántico relacionado con la fuente u origen de la información expresada en el enunciado" $(2005,16) .{ }^{11}$ En español, la evidencialidad no está asociada a un morfema como en otros idiomas, pero sí puede presentarse en diversas formas gramaticales, por ejemplo, en determinado usos de verbos como "parecer", "resultar" (Cornillie 1-5), o en la ubicación del sujeto en la oración y el uso de gerundios y tiempos verbales. Para Willet, este rasgo lingüístico se compone de dos tipos de evidencia: directa o indirecta. Dentro de la directa, la base de la información son los sentidos, y en el caso de la indirecta, la información es referida (de primera o segunda mano, o cuyo origen es el folclore) o inferida (53-63). Wachtmeister Bermúdez (2004) agrega que el modo de captar la información no siempre deviene de los sentidos, sino que también se podría hablar de una evidencia endofórica, es decir, de una experiencia del informante captada, ya no por sus sentidos, sino por su imaginación o deseo (11). Este tipo de evidencia es constitutiva del poema del arcediano (y de las crónicas coloniales y la épica en general), especialmente por la relación que se $\mathrm{da}$ en estos documentos entre verdad y verosimilitud y, en particular, por cómo se articula en ellas la historia y la poesía, en términos de la Poética, lo que ha sucedido y lo que podría suceder.

En primer lugar, en el poema la evidencia directa se marca en el prólogo mediante el uso de ciertos verbos por medio de los que el autor declara la fuente de su poema-testimonio: "procuré poner en escrito algo de lo que supe, entendí y vi en ellas [las provincias] en veinticuatro años que en aquel nuevo orbe peregriné" (Barco Centenera 61). En el nivel gramatical, los verbos saber, entender y ver tiene un orden no casual, pero tal vez sí causal. Como se mencionó antes, el poema comienza con la primera llegada de un grupo de españoles al Río de la Plata, en el pasado próximo al testimonio. La primera re-

10. Sobre la inserción de este poema en la tradición discursiva de la épica americana, ver Navascués (2016, 307-11) y Ortiz Gambetta (2016b, 65-86).

11. La evidencialidad no se había considerado gramaticalizada en el español, pero las últimas investigaciones sobre el tema dan cuenta de una modalidad epistémica en la gramática del español (Wachtmaister Bermúdez 2005, 2004; Cornillie). 
lación del enunciador con la historia narrada es la de saber: conocer la historia de las expediciones anteriores (la de Díaz de Solís y la de Pedro de Mendoza), dar cuenta de ellas (de las que no había documentación escrita conocida hasta entonces), relatar sus desgracias, marcar también, como en clave para la expedición de Ortiz de Zárate, el continuum del signo del infortunio. ${ }^{12}$ Luego vendrá la de entender: el sesgo cognitivo de la mentalidad europea se activaba al contacto de la realidad americana. En ese caso, a veces la realidad confirmaba lo esperado, como insiste Todorov en el caso de Colón (30-37), otras veces, se ajustaba a los datos nuevos de lo percibido por los sentidos, pero pocas veces la utopía, en un amplio sentido, remitía en el contacto de las nuevas tierras (Aínsa 39-41). En el nivel de la diégesis testimonial, apelar a la evidencia directa era un recurso de retórica y documentación, y, en último lugar, cobraba centralidad el ver, verbo de percepción sensible que servía como anclaje lingüístico y que permitía trazar el pacto con el lector. La información, pues, que presenta Barco Centenera es del tipo de experiencia directa, evidencia endofórica, fuentes librescas y testimonios y relatos de segunda mano.

Si distinguiéramos en apartados el texto de acuerdo a la fuente de la información que utiliza, se podría considerar una parte (los primeros cantos) en la que la voz épica hace referencia a los hechos que sucedieron antes de la llegada de la tripulación de Ortiz de Zárate y otra, a los hechos vividos en primera persona o en sincronicidad con la estadía del arcediano en la zona. En cuanto a estos últimos, la voz épica distingue los sucesos que se llevaron a cabo al mismo tiempo que el narrador testigo estaba en América, aunque en otro sitio, y los hechos que le sucedieron en primera persona. En estos, se encarga de reforzar el testimonio conforme era costumbre y por lo cual se diferenciaban y se valoraban de otra manera los textos indianos. Se podría decir que el valor documental en las llamadas crónicas como esta, muchas veces, superaba al valor estético, aunque varias obras alcanzaron los dos aspectos.

En cuanto a las fuentes, por otro lado, queda distinguir aquella información de segunda mano referida por el narrador o incluso aquella de raíz folclórica, algo que casi siempre aparece con el mismo nivel de tratamiento que los hechos donde la voz declara la evidencia directa como fuente de información. La mayor parte de los testimonios de Barco Centenera pospone el conocimiento libresco ante el empuje de la experiencia propia, forma de autori-

12. Para un análisis profundo y completo de la retórica del infortunio en textos coloniales latinoamericanos ver Carniero. 
dad compartida por autores contemporáneos al arcediano como Torquemada o Pérez de Moya (Navascués 2015, 75). La mayoría de las fuentes librescas referidas no son de las empresas conquistadoras sino que consisten en historias de España, el Laberinto de Fortuna, la Biblia, por poner algunos ejemplos. La instalación de la experiencia como origen del testimonio, las fuentes históricas y la declaración de sus informantes (a quienes ha oído, a quienes ha preguntado) construyen en los primeros cantos el sustento de la verosimilitud, aspecto que preocupó a todo cronista americano (Franco 40). Pero además de esta construcción testimonial, hay en el poeta un explícito deseo de agradar y de asegurar que su información es verdadera, casi bajo pena de ostracismo, tal como declara en los primeros versos al Marqués de Mora:

Que aunque en esta obra el fundamento primero y principal, Río de la Plata, y así es primero su descubrimiento, con todo no será mi pluma ingrata que aquí pintará al vivo lo que siento del nuevo orbe al marqués Mora; y si trata contrario a la verdad, yo sea borrado de su libro, y a olvido condenado. (Barco Centenera 66)

Lo curioso de este fragmento no es solo ese juramento de veracidad, sino que el poeta refiera que su pluma "pintará al vivo lo que siento", es decir, su texto incluirá información sobre la llegada europea a la región, pero también se comentarán las implicancias emocionales de la experiencia, como se podrá comprobar en muchas oportunidades, y especialmente, cuando relata los casos de la hambruna y los episodios grotescos y descarnados de antropofagia, los que alude en un presente de la enunciación luctuoso "Y así por no acordarme de tal llanto / de tan crudo dolor y triste suerte / quisiera fenecer en este canto" (144), "que solo al referirlo me da pena" (158), "Mas ay!, que en acordarme de tal cuento / temblando estoy, confuso y temeroso" (170).

Las fuentes de información de todo tipo que se aluden podrían ser una manera de decodificar el grado de confiabilidad de la información, y de su modalidad epistémica, de manera tal que si el hablante relata una experiencia sensorial directa o toma lo dicho de una autoridad en el área en cuestión, el compromiso con la información transmitida sería más alto (Watchmaister Bermúdez 2005, 8). Esta insistencia en transmitir una experiencia sensorial directa y de remarcar el grado de confiabilidad se refleja, por ejemplo, en el epi- 
sodio de los perros suicidas. En esta narración el uso reiterado del verbo "ver" confirma aquello que se había tomado de la fuente libresca, es decir, la mención de los hiperbóreos suicidas del De mirabilis mundi de Julio Solino (Barco Centenera 256) y que sirve de adelanto a la verificación de la información:

Parece que el morir les da contento y así muestran querer aquella muerte, $\mathrm{y}$ vemos frecuentemente aquel asiento de perros y morir aquella muerte.

Yo vide aquesto propio que aquí cuento.

Que por juzgar el caso por fuerte, a verlo fui, y los perros que allá fueron, bailando vi en la fuente perecieron. (Barco Centenera 256-57) ${ }^{13}$

Con el uso insistente del verbo "ver", aquí el arcediano busca remarcar la veracidad (Navascués 2015, 76), pero además "a verlo fui” muestra la intención de rastrear la fuente de segunda mano, confrontarla con el sentido externo, y establecer continuidad con la tradición de la fuente libresca. Pero, no conforme con atribuir su percepción del hecho mediante el sentido de la vista, el poeta también declara haber tenido contacto físico con otros seres extraordinarios:

A dos leguas entra otro, que es nombrado

el río negro Hum tiene por nombre.

Aquí en nuestros tiempos se han hallado

pescados semejantes mucho al hombre.

Aquesto de pasada lo he tocado,

ninguno de leerlo aquí se asombre. (Barco Centenera 80)

Luego de ir y comprobar con sus sentidos la existencia de los perros, y después de tocar los pescados muy parecidos a los hombres en sus formas, aparece otro episodio aún más fantasioso del que también el yo épico es testigo, y el cual se presenta como epítome de la enumeración progresiva de casos maravillosos:

Por un pequeño río de boscaje las balsas y la barca caminaban, cuando vimos venir un gran salvaje.

13. La cursiva es mía. 
La canoa en que viene, gobernaban

al parecer dos ninfas de buen traje. [...]

Por yelmo un cuero de anta en la cabeza,

el escudo era concha de pescado,

y el bastón que este bárbaro tenía

servir de antena en nave bien podía. (Barco Centenera 205)

$\mathrm{El}$ indígena, una suerte de gigante, dialoga con ellos y les advierte que los atacará. Hay una transcripción literal de su discurso, hay una narración de la pelea y de cómo después se marchan las ninfas y el gigante, pero estas, como las sirenas de la Odisea, "con dulce canto armonioso [...] a muchos el sentido enternecieron" (206). El uso de "vimos" da cuenta de una primera persona, esta vez plural, que permite la idea de una experiencia vivida en colectivo (y, de esa manera, certificada) y el sintagma "al parecer" vuelve a poner el foco en el punto de vista del sujeto que relata y que percibe con sus sentidos a estos seres que llama primero ninfas y a las que luego atribuye poder de encantamiento de sirenas.

Este es, sin duda, uno de los episodios más llamativos de experiencia directa del sujeto épico sobre personajes y atribuciones fantásticas, y sobre hechos concretos de enfrentamiento con el indígena. La persuasión afincada en los múltiples recursos retóricos aparece de manera insistente en el episodio mentado, cuyo relato se inicia con los versos: "Y oíd lo que sucede un día de Ramos / que de vista es el cuento que contamos" (Barco Centenera 204). En otros episodios, la estructura y la ubicación del yo épico tiene que ver con el exemplum, como se verá a continuación, alrededor del cual pivotan la función moral y la verosimilitud.

\section{LA ELEVACIÓN DEL SUJETO Y LA INFERENCIA EN EL USO DEL EXEMPLUM}

Como se ha mencionado, las fuentes librescas, los relatos de segunda mano, la percepción y la imaginación también están en la base de otro tópico presente en el texto: el relato de las maravillas. Los insumos de lo raro o maravilloso tienen un lugar de predominancia en el poema -de nuevo, como respuesta a una demanda-, pero además hay una insistencia en que el relato de la maravilla no es algo retórico, tal como se declara al comienzo del texto:

Tratar tengo también de sucedidos y extraños casos que iba yo notando. 
De vista muchos son; otros, oídos, que vine a descubrir yo preguntando, de personas me fueron referidos. (Barco Centenera 65)

Aquí hay una alusión a que los casos extraños y sucedidos que el poeta (un "yo" que emerge en determinados episodios y otras veces se diluye) "iba notando", fue "descubriendo preguntando" y fue referido por otros, como vimos en el caso de los perros suicidas. De esta manera, el enunciador declara las bases de la evidencialidad de su discurso: tiene una actitud activa en relación con la información, los hechos maravillosos se le presentan y él indaga, averigua, descubre y corrobora esos datos. Hay, de alguna manera, una intención empirista frente al florecimiento de testimonios y relatos apócrifos sobre viajes y relatos de lo maravilloso sobre América.

El registro de la maravilla en las crónicas de Indias aparece casi siempre en el formato de la anécdota y el exemplum, lo que facilitaba la introducción de un punto de vista del testimoniante que reforzaba, a su vez, lo curioso y lo veraz del relato. ${ }^{14}$ Esto hace suponer que parte del mencionado "descubrimiento" del autor consistía no solo en experimentar en carne propia sino también en ir recuperando casos extraordinarios que abultaran los insumos de lo narrado, en cuyos relatos aparecen también las marcas de evidencialidad. Por ejemplo, en el caso del carbunclo, animal mítico mencionado en las Soledades de Góngora, de quien Arellano (201-33) ha seguido la huella, y a quien Barco Centenera asegura haber visto "por propios ojos" (95) y lo menciona con su nombre en guaraní (Añang-Pitá). Algo similar sucede con las metamorfosis, el fénix que habitaba en Itapuá, todas tomadas de la "ciencia vulgar del siglo XV", al decir de Caillet-Bois (91). Pero también, en el poema de Barco Centenera, los exempla aparecen como inducción imperfecta y con una intención moralizante. Como sostiene Aragüés, durante el Renacimiento, los tratados morales hacían uso de los exempla como también lo hacían las crónicas históricas pero, a diferencia de estas, el discurso moralizante aceptaba cualquier forma de ejemplo (ficcional, verosímil, alegórico) con tal de que exhortara a la moral, al margen de su carácter histórico o ficticio (43). El tono moralizante del texto de Barco Centenera es constante y sus implicancias se vinculan muy estrechamente con las fuentes de información y el locus de enunciación.

14. Sobre este asunto, ver Oviedo. 
Así aparecen combinados el relato maravilloso y la ejemplificación en el relato de la pareja de infieles que se escapan y que luego el arcediano debe juzgar y castigar, donde aparece un pez con patas que persigue a la joven adúltera. La narración se articula, casi al final de la anécdota, nuevamente con la expresión "al parecer":

Un pece de espantable compostura, del mar salió reptando por el suelo.

Subióse ella huyendo en una altura, con gritos que ponía allá en el cielo.

El pece la siguió. La sin ventura

temblando está de miedo con gran duelo;

el pece con sus ojos la miraba,

y, al parecer, gemidos arrojaba. (Barco Centenera 159-60)

En su doble función (descriptiva y ejemplificadora) esta anécdota y otras del estilo amalgaman en el discurso lo que Francisco de Mendoza llama en Viridarium sacrae ac profanae eruditionis (1633) una "inducción imperfecta", ya que se induce algo a partir de un asunto individual. ${ }^{15}$ En suma, la enumeración de ejemplos funciona como recurso de argumentación de veracidad, y, en este caso, son piezas clave del relato testimonial.

Como se vio en la anécdota de la pareja de infieles y como analizaremos en otros casos, los marcadores de modalidad epistémica que construyen el locus de la enunciación apuntan a otros recursos para desmarcarse o para poner cierta distancia con lo narrado, como cuando se modifica el punto de vista, cuando se produce la "elevación del sujeto" o cuando se trabaja la inferencia. En cuanto al primer aspecto, el punto de vista fluctúa en varias ocasiones: como en Naufragios (1555) de Álvar Núñez Cabeza de Vaca, la voz del sujeto que narra se excluye de la narración de un hecho indigno, del que es testigo y da cuenta, para mantener, supuestamente, cierta jerarquía entre sus compañeros de tripulación (Molloy 428-34). El "yo" y el "nosotros" fluctúan en $A r$ gentina... como en Naufragios: el enunciador se incluye en el nosotros del relato en los momentos de regocijo pero se aleja del grupo en el momento de

15. La inducción puede ser imperfecta, tal como define Jevons: "Se llama perfecta una inducción, es decir, un acto de razonamiento inductivo, cuando se han examinado y enumerado en las premisas todos los casos a los que se refiere la conclusión. Si, como usualmente acontece, es imposible examinar todos los casos, puesto que pueden ocurrir en venideros tiempos, en partes remotas de la tierra o de otras regiones del universo, se llama la inducción imperfecta" (136). 
declarar las penalidades como, por ejemplo, cuando describe la reacción de todos durante una tormenta:

Aquí estuvo el armada reposando, tres días no cabales, que corría buen viento que nos iba convidando a tener regocijo y alegría.

Camina, pues, la armada algunas leguas, entregada a las ondas de Neptuno, y engolfada en el golfo de las Yeguas, sucede un vendaval tan importuno, que si Dios no pusiera presto treguas, de todos no escapara ni solo uno. $Y$ viendo andar el mar por las estrellas, de temor lloran hombres y doncellas. (Barco Centenera 145-46)

Como señala Silvia Molloy en relación con el fluctuante testimonio de Cabeza de Vaca, en donde se excluye de los relatos del hambre (434-35), en el poema del arcediano el poeta también muestra un distanciamiento de sus compañeros en ciertos episodios:

Pues los que están acá, en crudo llanto

están, y tan mudados y trocados

que solo con mirarlos dan espanto;

y están de verse tales admirados.

A muchos el pellejo como manto

les cubre aquellos huesos descarnados;

en otros, agua, humor corrupto, viento, entre pellejo y huesos han asiento. (Barco Centenera 157)

En las narraciones del hambre vivido por las tripulaciones del Río de la Plata, también el sujeto épico declara haber probado una clase de carne que no era digna de su condición: el adelantado Cabeza de Vaca prueba los perros (Cabeza de Vaca 23), Barco hace lo propio con las lagartijas: "yo bien oso decir que las comí" (Barco Centenera 335) y luego, agrega, esa carne "más que de cabritos parecía” (335). Pero el distanciamiento de los otros compañeros es más marcado cuando se trata de carne humana, al igual que sucede en Naufragios (Molloy 433). Conforme se presenta la degradación de la hambruna y la declaración de la percepción sensible de la antropofagia, se evocan los actos 
de canibalismo mediante el recurso de la elevación del sujeto, ${ }^{16}$ con sintagmas como "vi que se comía" (que, además de crear distancia con lo narrado, afirman su calidad de testigo) y "al parecer", entre otros:

La cosa a tal extremo hubo llegado, que carne humana vi que se comía.

Hambre canina fuerza allí a un soldado, pensando que su hecho nadie vía.

Las tripas le sacara a un ahorcado, y al medio del cocer se las comía.

Los huesos se roían de finados, ¿quién no llora estos casos desastrados? (Barco Centenera 162)

Así, esta elevación permite no identificar de entrada quiénes y cuántos se dieron al canibalismo, aunque el dato del soldado anónimo pareciera ilustrar lo antedicho. Lo central aquí es el sujeto principal de la acción, el testigo, y el grado de evidencialidad, en este caso, su percepción directa pero mediatizada por la distancia, un sujeto elevado moral, mental y gramaticalmente por encima de la situación.

Por último, como en este episodio donde supone el poeta que el soldado comía al ahorcado ("pensando que su hecho nadie vía"), hay otros ejemplos del uso de la inferencia en anécdotas ajenas que reelabora el yo épico para dar una mirada más abarcadora de los hechos. En varias ocasiones, el poeta reconstruye pensamiento de sus personajes (del soldado, de los amantes descubiertos), pero también se encarga de relatar aquellos sucesos de las expediciones escindidas de la principal, mientras el arcediano permanecía en el real, como es el caso de la flota que se había quedado en San Vicente:

Pudieran bien decir los doloridos, estando en Sant Vicente reposados, si nosotros no fuéramos perdidos, por ser de nuestra flota ya apartados, o fuéramos de hambre consumidos, o muertos de los indios y acabados;

16. La "elevación del sujeto" es una configuración de corte metonímico "en la que se evoca una entidad (la escena completa de la cláusula subordinada) por medio de la mención explícita de otra (su sujeto) que es más saliente, de más interés o más fácilmente codificada" (Langacker en Wachtmeister Bermúdez 2005, 19). 
y cierto para haber de guarecernos,

el medio más seguro fue perdernos. (Barco Centenera 148-49)

Sin dar cuenta de la fuente de la información sobre lo que había pasado en San Vicente, el poeta reconstruye la escena, asume las suposiciones y los deseos de la perdida expedición logrando así una escena llena de patetismo para la que recurre a la inferencia y también, como en otras ocasiones, a la preterición, el recurso de dar al lector la terea de completar con su imaginación la escena, que por decoro, no se quiere contar, el "imagínense ustedes" al que también recurre Núñez Cabeza de Vaca (Glanz 34) que se da en varias ocasiones. En suma, los casos en forma de exemplum, desde un sentido moral hasta un sentido descriptivo, configuran el recurso de la argumentación de la inducción imperfecta, procedimiento que confirma la validez de lo narrado.

\section{CONCLUSIONES}

En la Historia verdadera de la conquista de la Nueva España, Bernal Díaz del Castillo hacía referencia al texto de López de Gómara y otros cuyas sus fuentes de lo narrado eran historias conocidas "de oídas". Contra el desajuste y la exageración de esas narraciones, Díaz escribe su versión de los hechos, vividos en primera persona: "diremos lo que en aquellos tiempos nos hallamos ser verdad, como testigos de vista, e no estamos hablando (de) las contrariedades e falsas relaciones (como decimos) de los que escribieron de oídas" (74). La contraposición entre las fuentes de la evidencia para la escritura de un texto cronístico (lo oído contra lo visto) marcaba así el rumbo de la escritura sobre América, en los comienzos de una revolución epistemológica de la disciplina. En los poemas épicos americanos del siglo XVI y el XVII confluían la validez de la fuente testimonial, el discurso imperialista y moralista, y la entidad de la épica que estaba pasando de ser un discurso histórico de gran categoría para convertirse en una forma antigua.

En el caso del poema Argentina y conquista del Río de la Plata hay una clara pretensión de remarcar la veracidad de fuentes de segunda mano y la eminencia de la vista y el oído del testigo. Pero aún es necesario entender el empleo de lo fictivo como recurso retórico en pos de la persuasión con fines morales. El uso de relatos maravillosos de la tradición medieval, entre otros, fue vehículo para el mensaje en clave de exemplum: el contenido antiépico del poema encierra, de hecho, una lección de ética para todos aquellos a quienes la ambición llevó a aquellas tierras americanas, y en especial, para Juan Ortiz 
de Zárate como cabeza ejemplar de la inmoralidad. Las consecuencias de tal ambición fueron la hambruna, los naufragios y enfrentamientos contra los indígenas. El yo épico construye su relato apoyado en ciertos marcadores de evidencialidad y en un lugar de la enunciación en el que elude la controversia: haciendo uso de su condición de confesor y jefe espiritual de la tripulación, emplea la marca gramatical de la elevación del sujeto como señal de superioridad moral. Esa cercanía distante con los hechos narrados y su pretendida elevación por encima de las circunstancias eran necesarios en el momento de la edición del poema: la nueva función como capellán en el virreinato de Portugal, el momento de rendir cuentas y dejar en alto su nombre, más allá de las causas legales que Barco Centenera había tenido en América.

En suma, Argentina... y la épica americana en general se deben considerar como textos de divulgación, reconocimiento y rendición de cuentas que implicaban una cosmovisión y un concepto de verosimilitud que un paradigma racionalista contemporáneo -en el cual, por otro lado, está basado la categoría de evidencialidad- no podría compartir del todo. Sin embargo, en este tipo de texto el sujeto desea ser fiel a su experiencia y su verdad, aun cuando ellas incluyan las lecturas previas, los elementos fantásticos asumidos en el código de los viajes a Indias, los dichos y relatos mentados, así como las inferencias, todo un modo retórico (y epistemológico) de acercarse a la realidad. Así, cabría en el análisis de un texto colonial y especialmente en un poema épico de esta índole, lo que Georges Steiner sostiene en Presencias Reales: "la verdad expresada es, ontológica y lógicamente, «ficción verdadera», donde la etimología de ficción remite de forma inmediata al de «hacer»" (74). En un discurso renacentista como el de Barco Centenera un testigo dice que es verdad lo dicho porque fue visto y oído y esta aseveración sella el pacto de lectura. Entender esto como una "ficción verdadera" implica tener en cuenta el horizonte cultural de ese "hacer": el uso de los recursos retóricos para la persuasión y el deleite, y el empleo del exemplum como inducción imperfecta.

\section{OBRAS CITADAS}

Adorno, Rolena. "Nuevas perspectivas en los estudios literarios coloniales hispanoamericanos". Revista de Crítica Literaria Latinoamericana 28 (1988): 11-37.

Aínsa, Fernando. De la Edad de Oro a El dorado: génesis del discurso utópico americano. México: FCE, 1992. 
Añón, Valeria. "Los usos del archivo: reflexiones situadas sobre literatura y discurso colonial". (In)disciplinar la investigación: archivo, trabajo de campo y escritura. Eds. Mario Rufer y Frida Gorbach. México: Siglo XXI/UAM, 2016. 251-74.

Aragüés, José. Deus concionator: mundo predicado y retórica del exemplum en los siglos de oro. Amsterdam: Rodopi, 1999.

Arellano, Ignacio. "Un pasaje oscuro de Góngora aclarado: el animal tenebroso de la Soledad primera (vv. 64-83)". Criticón 120-121 (2014): 201-33. 12 de diciembre de 2017. <http://journals.openedition.org/criticon/901>.

Azara, Félix. Descripción e bistoria del Paraguay y del Río de la Plata. Buenos Aires: Bajel, 1943.

Barco Centenera, Martín del. Argentina y conquista del Río de la Plata. Ed. Silvia Tieffemberg. Buenos Aires: Eudeba, 1998.

Cabeza de Vaca, Álvar Núñez. Naufragios. Valladolid, 1555.

Caillet-Bois, Julio. "La Argentina de Martín del Barco Centenera". Historia de la literatura argentina. Dir. Rafael Arrieta. Buenos Aires: Peuser, 1958. 81-95.

Carniero, Sarissa. Retórica del infortunio: persuasión, deleite y ejemplaridad en el siglo ХVI. Madrid: Iberoamericana/Frankfurt am Main: Vervuert, 2015.

Cornillie, Bert. Evidentiality and Epistemic Modality in Spanish (Semi-)Auxiliaries: A Cognitive-Functional Approach. Berlin: Mouton de Gruyter, 2007.

Díaz del Castillo, Bernal. Historia verdadera de la conquista de la Nueva España. Vol. 1. Madrid: Imprenta de Don Benito Cano, 1795.

Durán, Juan Guillermo. Monumenta cathechetica bispanoamericana: siglos XVIXVIII. Vol. 2. Buenos Aires: Facultad de Teología UCA, 1990.

Firbas, Paul, ed. Épica y colonia: ensayos sobre el género épico en Iberoamérica (siglos ХИ у ХИІІ). Lima: UNMSM, 2008.

Franco, Jean. "La cultura hispanoamericana en la época colonial". Historia de la literatura hispanoamericana. Eds. Luis Íñigo Madrigal y Manuel Alvar. Madrid: Cátedra, 2008. 35-53.

Gandía, Enrique. "Vida de Martín del Barco Centenera". Revista del Instituto Argentino de Ciencias Genealógicas 4.4-5 (1945): 52-111.

Glanz, Margo. "El cuerpo inscrito y el texto escrito o la desnudez como naufragio". Revista Universidad de México 496 (1992): 32-42.

Gutiérrez, Juan María. "Estudio sobre La Argentina y conquista del Río de la Plata y sobre su autor Don Martín del Barco Centenera”. Martín del Barco Centenera. La Argentina. Poema bistórico. Reimpresión fascimilar de la primera edición de Lisboa 1602. Buenos Aires: Peuser, 1912. 3-270. 
Jevons, William Stanley. Lecciones elementales de lógica deductiva e inductiva: con gran copia de preguntas y de ejemplos, y con un vocabulario de términos lógicos. Madrid: Secretaría de Fomento, 1893.

Marrero-Fente, Raúl. Poesía épica colonial del siglo XV: historia, teoría y práctica. Madrid: Iberoamericana/Frankfurt am Main: Vervuert, 2017.

Mignolo, Walter. "Second Thoughts on The Darker Side of the Renaissance: Afterword to the Second Edition". The Darker Side of the Renaissance. Michigan: Michigan UP, 2003. 427-81.

Molloy, Sylvia. "Alteridad y reconocimiento en los Naufragios de Alvar Núñez Cabeza de Vaca". Nueva Revista de Filología Hispánica 35.2 (1987): 425-49.

Montaner Frutos, Alberto. "Épica, historicidad, historificación”. El Poema de Mio Cid y la épica medieval castellana: nuevas aproximaciones críticas. Eds. Juan C. Conde y Amaranta Saguar. London: Queen Mary/University of London, 2015. 17-53.

Navascués, Javier de. "Monstruos de ultramar y reinos imaginarios en Argentina y conquista del Río de la Plata, de Martín del Barco Centenera". Romance Notes 55 (2015): 73-82.

Navascués, Javier de. "Molde épico y mirada antiheroica en Argentina y conquista del Río de la Plata". Clásicos para un nuevo mundo: estudios sobre la tradición clásica en la América de los siglos XVI y XVII. Ed. Bernat Garí. Bellaterra: UAB, 2016. 307-26.

Oesterreicher, Wulf. "Estudio introductorio". Alonso Barragán. La conquista del Perú. Eds. Eva Stoll y M. N. Vázquez. Madrid: Iberoamericana/ Frankfurt am Main: Vervuert, 2011. 11-56.

Ortiz Gambetta, Eugenia. "La leyenda aborigen en la lírica de Gutiérrez y Berro". Verba Hispanica 24 (2016a): 201-15.

Ortiz Gambetta, Eugenia. "Heteroglosia y tradiciones discursivas: formas burlescas en la épica de M. del Barco Centenera". Hipogrifo: revista de cultura y literatura del Siglo de Oro 4.1 (2016b): 65-86.

Oviedo Pérez de Tudela, Rocío. "La anécdota en la Crónica de Indias". Congreso Internacional Italia, Iberia y el Nuevo Mundo. Presencias culturales italianas e ibéricas en el Nuevo Mundo; Miguel Ángel Asturias. Aspectos y problemas de la narrativa del siglo XX. Eds. Clara Campani, Marjorie Sánchez y Patrizia Spinatto. Roma: Bulzoni, 1997. 187-206.

Pierce, Frank. La poesía épica del Siglo de Oro. Trad. J. C. Cayol de Bethencourt. Madrid: Gredos, 1968. 
Rojas, Ricardo. Historia de la literatura argentina: los coloniales. Vol. 1. Buenos Aires: Losada, 1948.

Steiner, Georges. Presencias reales: ¿hay algo en lo que decimos? Trad. Juan G. López Guix. Barcelona: Destino, 1991.

Todorov, Tzvetan. La conquista de América: el problema del otro. Trad. Flora Botton. México: Siglo XXI, 1982.

Vega, María José. "Idea de la épica en la España del Quinientos". La teoría de la épica en el siglo ХVI (España, Francia, Italia y Portugal). Eds. María José Vega y Lara Vilà. Vigo: Academia Editorial del Hispanismo, 2010. 103-35.

Vega, María José, y Lara Vilà, eds. La teoría de la épica en el siglo XVI (España, Francia, Italia y Portugal). Vigo: Academia del Hispanismo, 2010.

Wachtmeister Bermúdez, Fernando. "La categoría evidencial del castellano: metonimia y elevación del sujeto". Boletín de Linguiística 22 (2004): 3-31.

Wachtmeister Bermúdez, Fernando. Evidencialidad: la codificación lingüística del punto de vista. 2005. Stockholm University, PhD Dissertation.

Willet, Thomas. "A Cross-Linguistic Survey of the Grammaticalization of Evidentiality". Studies in Language 12.1 (1988): 51-97.

Wright, Ione S., y Lisa M. Nekhom. Diccionario bistórico argentino. Buenos Aires: Emecé, 1990. 